\title{
UNA MIRADA SOBRE PRINCIPIOS EN EL PROCEDIMIENTO DE MEDIACIÓN
}

\section{Carla Saad ${ }^{1}$}

\section{Resumen}

La Mediación se presenta como una técnica aplicada a la resolución pacífica de conflictos alternativa al sistema judicial argentino. El trabajo aborda la determinación de principios propios de la Mediación, para ello se compara la enunciación de principios en la legislación provincial y nacional, la determinación de éstos en doctrina, para finalizar con una valoración crítica sobre la determinación y jerarquía de principios propios de la Mediación, desde los parámetros del pensamiento complejo. Como es un estudio que integra un programa de investigación sobre resolución de conflictos en familias, el análisis es un aporte que complementa los aplicables a los procesos de resolución de conflictos familiares.

Palabras claves: Mediación - Principios - Resolución pacífica de conflictos - Procesos de resolución de conflictos en Argentina

\section{INTRODUCCIÓN}

La Mediación es una de las formas de resolver conflictos que complementa el sistema de modalidades existentes para abordar una posible resolución. El complejo sistema de resolución está formado por métodos conocidos, tanto el método tradicional como es la resolución vía judicial o por una multiplicidad diversa y rica de modos que se diferencian de éste último, como opción válida de autocomposición de las partes para intentar "sanar" sus relaciones de conflicto.

Las disputas y las controversias son un fenómeno inevitable en toda sociedad; cuando personas con diferentes intereses se relacionan entre sí, surgirán invariablemente divergencias de distinto tipo e intensidad. Existirán siempre interpretaciones dispares de cláusulas contractuales y de los derechos que corresponden a cada uno. La solución tradicional --aquella para la cual se nos ha preparado-- es depositar esas disputas en los tribunales estatales, transfiriendo a los jueces la carga de resolverlos mediante la adjudicación del derecho de cada parte. Está a la vista que los costos de este sistema --individual y socialmente considerados-- son muy altos: sobrecarga crítica de los despachos judiciales e ineficiente protección de los reales intereses de las partes; se dilapida tiempo y otros

\footnotetext{
${ }^{1}$ Doctoranda e Investigadora del Centro de Investigaciones Jurídicas y Sociales, Profesora "Teorías del Conflicto y de la Decisión. Métodos de Resolución Pacífica de Conflictos", Tutora Académica "Práctica Profesional III" de la Facultad de Derecho, Universidad Nacional de Córdoba. Directora del proyecto "Impacto de los Derechos Fundamentales en los derechos de las vol.09, nº. 04, Rio de Janeiro, 2016. pp. 1913-1934 1913
} 
valiosos recursos económicos que son desviados de la fase productiva. Frente a realidades similares --y quizá de menor gravedad que la Argentina-- otros países han encarado un profundo cambio, generando un movimiento en favor de los sistemas alternativos de resolución de disputas, como vías para reducir la litigiosidad improductiva y lograr mejores relaciones humanas entre las partes (Caivano:1994).

Desde los años 1990, la Mediación es una técnica que se introduce en la consideración de los operadores jurídicos argentinos, reacios a cambios, pero que tuvieron que adecuarse vía imposición legislativa a la utilización del método. Más de veinte años han transcurrido de historia y en la actualidad, en vistas a la implementación del reformado Código Civil y Comercial, la Mediación se muestra como un método de creciente implementación en nuestra cultura jurídica.

Es motivo de este trabajo, reconociendo a la Mediación como una técnica de resolver conflictos, indagar sobre la existencia de principios que rijan su procedimiento. Para ello, la mirada estará puesta sobre el instituto visto como un posible procedimiento y, de allí, indagar sobre la existencia de principios que guíen el mismo.

\section{¿PODEMOS HABLAR DE PROCEDIMIENTO EN MEDIACIÓN?}

De las múltiples definiciones sobre mediación rescatamos aquellas categorizaciones que incluyen al procedimiento, así Folber y Taylor (1992:27). la definen como "el proceso mediante el cual los participantes, junto con la asistencia de una persona o personas neutrales, aíslan sistemáticamente los problemas en disputa con el objeto de encontrar opciones, considerar alternativas, y llegar a un acuerdo mutuo que se ajuste a sus necesidades"

Caram, Eilbaum y Risolía (2013:17), al momento de analizar distintas definiciones coinciden en concluir que la Mediación es "un hacer" y que su práctica es "el proceso en el que un tercero neutral, a solicitud de las partes, los asiste en una negociación colaborativa, en la que sus diferencias son replanteadas en términos de intereses, a fin de que puedan ellos tomar una decisión satisfactoria con relación a los mismos".

Enrolados en el concepto que comprende a la Mediación como "un hacer" y que ese "hacer" se cristaliza en un procedimiento que cuenta con un conjunto de recursos de que se sirve, es decir, adquiere el valor de técnica.

Esta técnica dada en una fuerza ordenadora por la que es dirigida, conjuga recursos que se ordenan en un proceso que, en su origen y alejado del procedimiento judicial, pretende acompañar en sintonía y con cierta organización, cuya flexibilidad acompañe el delicado devenir de la relación de conflicto confiada a su tratamiento.

Técnica, diferenciada del proceso judicial y como tal, independiente de la existencia viva del método tradicional. Sus presupuestos diferenciados, no son excluyentes del proceso judicial, sino que ambos forman parte 
de un complejo ${ }^{2}$ sistema de abordaje de un conflicto, complementándose, en diálogo, formando parte de ese "movimiento" de constante tensión en las relaciones de conflicto.

Como expresáramos, esta técnica tiene un proceso en el que pone en juego los recursos hábiles para la consecución del método. Proceso, entendido como procedimiento, como la secuencia de recursos seguida por el mediador que dirigiendo el mismo, facilita la comunicación entre partes para el tratamiento de su relación de conflicto.

Como "proceso" también cuenta con principios que guiarán su devenir. Nuestra tarea ahora será definir cuál es la mirada que ensayamos sobre los principios que rigen al proceso de mediación.

\section{CUANDO DE PRINCIPIOS HABLAMOS}

Cuando de "principios" se trata la posición doctrinaria sobre su definición, jerarquía, función, entre otros temas referidos, no es unánime, debatiéndose en amplio abanico desde diferentes corrientes: desde el iusnaturalismo pasando por la dogmática, el pensamiento complejo y el llamado "derecho por principios".

Estos principios generales que fueron entendidos como normas del derecho natural, posteriormente ante la existencia de sistemas normativos, se fundamentó su existencia únicamente en el derecho positivo. No es motivo de este trabajo ahondar sobre cada doctrina, pero sí plantearnos un posible escenario hacia una construcción epistemológica que sustente nuestro trabajo.

Entonces, encontramos posturas afines a definir los "principios" como directrices consagradas por la ley para su propia interpretación y posturas que superan su recepción normativa para afirmar que existe antes de su expresión legislativa e, incluso, después de su formal formulación.

Ferreyra de de la Rúa y González de la Vega de Opl (1994:17), al momento de definir los principios de la prueba, consignan "los principios son directrices que se imponen en una legislación y que servirán para interpretar las reglas de cada medio probatorio y así resolver adecuadamente los problemas que plantee su diligenciamiento".

Capón Filas (2010:279), al discurrir sobre principios generales, entiende que son criterios de valor, que nacen de la dignidad humana y profundizando su razonamiento expresa, "son criterios axiológicos anteriores a las normas, para sancionar las convenientes y aplicarlas de modo adecuado. Si bien algunos pueden haber sido receptados normativamente, importa señalar su ubicación anterior. Esto conlleva a que, a medida que se consolide la conciencia de los Derechos Humanos, los constructores podrán expresar nuevos principios o encontrar mayores contenidos a los existentes".

\footnotetext{
${ }^{2}$ El término "complejo" está expresado en la clara extensión que Morin imprime al caracterizar el pensamiento complejo en su obra: MORIN, Edgar. Introducción al pensamiento complejo, Editorial Gedisa S.A., España, 1990, pág. 87-110. vol.09, nº. 04, Rio de Janeiro, 2016. pp. 1913-1934 
En cambio, García Cima de Esteve (2015:6) analizando el llamado "derecho por principios", más precisamente bajo el subtítulo "pluralidad de principios" nos enseña que "la pluralidad de principios sin jerarquización formal entre ellos, permite a las ciencias su articulación, mediante la ponderación amplia y profunda, en las situaciones concretas de la vida social que se iluminan con los múltiples valores que encierran los principios del derecho de que se trata", y frente a la posible contradicciones, profundiza "además la naturaleza relativizable, de los principios y de los valores, al contrario de la ética y de las reglas jurídicas que no lo son, hace posible que en caso de contradicciones entre ellos, se concilien recíprocamente, en la búsqueda de una más ponderada respuesta al caso concreto".

Creemos necesario aclarar que al hablar de principios, involucramos los conceptos aplicados a los "generales del derecho" como aquellos de una especialidad, esto es así por cuanto percibimos al derecho como un verdadero sistema del que cualquier concepto participa, en necesaria relación, con los otros de su sistema o -bajo una mirada interdisciplinaria- de otros sistemas como verdaderas redes integradoras de la sociedad.

Nos alienta pensar en una sociedad que construya sus bases en la más alta expresión de su humanidad (Derechos Humanos). Es interesante profundizar también en los modelos de pensamiento, analizando cómo estos principios impactan en construcciones legislativas hasta un modelo moderno de "derecho por principios", cuestión que escapa al desarrollo del presente trabajo.

Nos queda construir una definición de "principios" que guie nuestro pensamiento. Serán -a nuestro entender- aquellos criterios axiológicos que existen "en y a pesar" de la norma, que participan de un sistema complejo dado en una cultura, tiempo y lugar por lo tanto se alimentan y retroalimentan de ella, y pueden ser compartidos por las individualidades de sus disciplinas, complementándose.

\section{LA MEDIACIÓN Y SUS PRINCIPIOS}

\section{Los principios "en".}

En Argentina, la Mediación como técnica de resolución de conflictos en su desarrollo tecnológico actual, es de reciente implementación. A comienzos de la década de los años '90, se construye el "Plan Nacional de Mediación" desarrollado por una Comisión de Mediación ${ }^{3}$ en el seno del Ministerio de Justicia de la Nación. Este impulso inicial, fue tomando forma en las diferentes jurisdicciones y foros de doctrinarios a fin de lograr, primero una información y conciencia sobre las ventajas del método, capacitar a los operadores del derecho para lograr una paulatina incorporación a la conciencia jurídica de resolución de conflictos cuyo eje -hasta entonces- era casi con exclusividad, el procedimiento judicial. En Córdoba, aún sin marco legal regulatorio, se inaugura el Centro de 
Arbitraje, Mediación y Resolución Concertada de Conflictos $^{4}$ (CAMERECC), en el marco de una visionaria acción institucional en el Colegio de Escribanos de la Provincia de Córdoba que sirvió de precedente a la Ley de Mediación 8858 en el desarrollo del instituto en sede extrajudicial, multidisciplinario y voluntario ${ }^{5}$.

A pesar de estos auspiciosos proyectos de políticas públicas y privadas en torno al fomento de otras formas de resolver conflictos, la reticencia del cambio cultural de los operadores jurídicos del momento era notoria. Las razones, varias: falta de confiabilidad en el método, apego al procedimiento judicial, falta de legitimación en el empoderamiento de las partes para resolver sus conflictos, sentimiento de ataque a la competencia profesional del abogado, entre otras. La decidida política pública de implementación encontró respuesta a esta problemática en la redacción de normas que impusieran la paradoja de incorporar la "obligatoriedad" en el acceso a la Mediación, pero no en la continuación y finalización con acuerdo del proceso. Coincidimos con García Cima cuando expresa que si bien es comprensible la necesidad de recurrir a algún medio para favorecer la aceptación de este cambio de actitud frente al conflicto, no podemos dejar de manifestar nuestra opinión en contrario, y en cambio propiciar otras medidas que, sin ser coactivas, compartan las características y las ideas que sustentan la mediación como modelo de cambio cultural frente al conflicto.. (García de Esteve: 2015).

Actualmente, la nación y la mayoría de las provincias tienen normativas ${ }^{6}$ que incorporan la Mediación al sistema reconocido de resolución de conflictos y, en ellas se enumeran diferentes "principios", que luego de un análisis comparativo, encontramos como construcciones receptadas por el sistema normativo.

1. Voluntariedad ${ }^{7}$

2. Libertad $^{8}$

3. Comparecencia personal de las partes ${ }^{9}$

4. Inmediatez ${ }^{10}$

\footnotetext{
${ }^{3}$ La Comisión fue integrada por los Dres. Elena I. Highton, Gladys Alvarez, Luis Gaibrois, Zulema Wilde, Carlos Arianna y Eduardo Zannoni.

${ }^{4}$ El diseño y dirección del Centro de Arbitraje, Mediación y Resolución Concertada de Conflictos (CAMERECC) estuvo a cargo de la Dra. Elena García Cima de Esteve (1997-2000).

${ }^{5}$ Para mayor ilustración sobre los antecedentes de la Mediación en el mundo, Argentina y Córdoba se puede ampliar el tema, entre otros, HIGHTON, Elena I.; ALVAREZ, Gladys. Mediación para resolver conflictos, AD-HOC S.R.L. (tercera reimpresión), Buenos Aires, 2008 y GARCIA CIMA DE ESTEVE, Elena. Un diseño de mediación-Modelo del Colegio de Escribanos de Córdoba, Argentina, Alveroni Ediciones, Córdoba, 2001.

${ }^{6}$ Entendemos por normativa, no solamente las leyes que regulen su ejercicio, sino también las Constituciones Provinciales, Acordadas, Protocolos y Programas que fueran clasificadas de la fuente, www.csjn.gob.ar, búsqueda del 7 de julio de 2015. Agradecemos la colaboración del Ab. Fabrizio Suarez.

${ }^{7}$ Nación, Ley N²5.689, artículo 7; CABA, Ley N²451, Régimen Procesal Penal Juvenil de la Ciudad Autónoma de Buenos Aires, artículo 56; Buenos Aires, Ley 13951, Régimen de Mediación, artículo 1; Misiones, Ley XII 19 (antes Ley 4517), artículo 5; Neuquén, Programa de Mediación Penal (Ley 2302, artículo 64), artículo 6; Río Negro, Ley de Mediación 3847 (hoy P 3847 ), artículo 3; San Juan, Ley 7454, artículo 2; Tierra del Fuego, Ley de Mediación 804, artículo 2.

${ }^{8}$ Nación, Ley $N^{\circ} 25.689$, artículo 7.

${ }^{9}$ Misiones, Ley XII 19 (antes Ley 4517), artículo 5.

${ }^{10}$ Misiones, Ley XII 19 (antes Ley 4517), artículo 5; Neuquén, Programa de Mediación Penal (Ley 2302, artículo 64), artículo 6; Río Negro, Ley de Mediación 3847 (hoy P 3847), artículo 3.
} 
5. Confidencialidad ${ }^{11}$

6. Celeridad ${ }^{12}$

7. Comunicación directa de las partes ${ }^{13}$

8. Satisfactoria composición de intereses ${ }^{14}$

9. Protagonismo y autodeterminación de las partes ${ }^{15}$

10. Informalidad ${ }^{16}$

11. Gratuidad ${ }^{17}$

12. Neutralidad ${ }^{18}$

13. Imparcialidad ${ }^{19}$

14. Igualdad ${ }^{20}$

\footnotetext{
${ }^{11}$ Nación, Ley N 25.689 , artículo 7; CABA, Ley № 2451, Régimen Procesal Penal Juvenil de la Ciudad Autónoma de Buenos Aires, artículo 56; Ley 13.433, Provincia de Buenos Aires, Mediación en lo Penal, artículo 3; Provincia Buenos Aires, Ley 13951, Régimen de Mediación, artículo 1; Córdoba, Ley 8858, artículo 4; Corrientes, Ley de Mediación 5487, artículo 4 y Procedimiento de Mediación Civil y Penal, Ley 5931, artículo 4; Chaco, Ley de Mediación 4498, artículos 3, 4 y 7; Entre Ríos, Código Procesal Civil y Comercial, Ley 9776, artículo 287; Formosa, Acordada 2612/10, Tribunal Superior de Justicia, pto 4; La Pampa, Ley de Mediación Integral 2699, artículo 3; Misiones, Ley XII 19 (antes Ley 4517), artículo 5; Neuquén, Programa de Mediación Penal (Ley 2302, artículo 64), artículo 6; Río Negro, Ley de Mediación 3847 (hoy P 3847), artículo 3; Salta, Mediación Ley 7324, artículo 4; San Juan, Ley 7454, artículo 2; Tierra del Fuego, Ley de Mediación 804, artículo 2; Tucumán, Mediación Previa Ley 7844 , artículo 7.

${ }^{12}$ Nación, Ley N ${ }^{\circ} 25.689$, artículo 7; CABA, Ley N 2451 , Régimen Procesal Penal Juvenil de la Ciudad Autónoma de Buenos Aires, artículo 56; Ley 13.433, Provincia de Buenos Aires, Mediación en lo Penal, artículo 3; La Pampa, Ley de Mediación Integral 2699, artículo 3; Misiones, Ley XII 19 (antes Ley 4517), artículo 5; Neuquén, Programa de Mediación Penal (Ley 2302, artículo 64), artículo 6; Río Negro, Ley de Mediación 3847 (hoy P 3847), artículo 3; Tierra del Fuego, Ley de Mediación 804, artículo 2. ${ }^{13}$ Nación, Ley № 25.689, artículo 7; Córdoba, Ley 8858, artículo 4; La Pampa, Ley de Mediación Integral 2699, artículo 3; Salta, Mediación Ley 7324, artículo 4; San Juan, Ley 7454, artículo 2; Tierra del Fuego, Ley de Mediación 804, artículo 2; Tucumán, Mediación Previa Ley 7844, artículo 7.

${ }^{14}$ Córdoba, Ley 8858, artículo 4; La Pampa, Ley de Mediación Integral 2699, artículo 3; Salta, Mediación Ley 7324, artículo 4; San Juan, Ley 7454, artículo 2; Tierra del Fuego, Ley de Mediación 804, artículo 2 (con la fórmula "composición de intereses, sin "satisfactoria"); Tucumán, Mediación Previa Ley 7844, artículo 7.

${ }^{15}$ Corrientes, Ley de Mediación 5487, artículo 4 y Procedimiento de Mediación Civil y Penal, Ley 5931, artículo 4; Misiones, Ley XII 19 (antes Ley 4517), artículo 5; Salta, Mediación Ley 7324, artículo 4 (como autodeterminación de las partes);San Juan, Ley 7454 , artículo 2.

${ }^{16}$ CABA, Ley N²451, Régimen Procesal Penal Juvenil de la Ciudad Autónoma de Buenos Aires, artículo 56.

${ }^{17}$ CABA, Ley N²451, Régimen Procesal Penal Juvenil de la Ciudad Autónoma de Buenos Aires, artículo 56.

${ }^{18}$ CABA, Ley N ${ }^{\circ}$ 2451, Régimen Procesal Penal Juvenil de la Ciudad Autónoma de Buenos Aires, artículo 56; Buenos Aires, Ley 13951, Régimen de Mediación, artículo 1; Córdoba, Ley 8858, artículo 4; Corrientes, Ley de Mediación 5487, artículo 4 y Procedimiento de Mediación Civil y Penal, Ley 5931, artículo 4; Chaco, Ley de Mediación 4498, artículos 3, 4 y 7; Chaco, Ley de Mediación 4498, artículos 3, 4 y 7; Entre Ríos, Código Procesal Civil y Comercial, Ley 9776, artículo 287; La Pampa, Ley de Mediación Integral 2699, artículo 3; Misiones, Ley XII 19 (antes Ley 4517), artículo 5; Programa de Mediación Penal (Ley 2302, artículo 64), artículo 6; Río Negro, Ley de Mediación 3847 (hoy P 3847), artículo 3; Salta, Mediación Ley 7324, artículo 4; Tierra del Fuego, Ley de Mediación 804, artículo 2; Tucumán, Mediación Previa Ley 7844, artículo 7.

${ }^{19}$ Nación, Ley N ${ }^{\circ} 25.689$, artículo 7; CABA, Ley N 2451 , Régimen Procesal Penal Juvenil de la Ciudad Autónoma de Buenos Aires, artículo 56; Buenos Aires, Ley 13951, Régimen de Mediación, artículo 1; La Pampa, Ley de Mediación Integral 2699, artículo 3; Programa de Mediación Penal (Ley 2302, artículo 64), artículo 6; Río Negro, Ley de Mediación 3847 (hoy P 3847), artículo 3; Tierra del Fuego, Ley de Mediación 804, artículo 2.

${ }^{20}$ Nación, Ley N²5.689, artículo 7; La Pampa, Ley de Mediación Integral 2699, artículo 3; Misiones, Ley XII 19 (antes Ley 4517), artículo 5; Programa de Mediación Penal (Ley 2302, artículo 64), artículo 6; Río Negro, Ley de Mediación 3847 (hoy P 3847), artículo 3.
} 
15. Consentimiento informado ${ }^{21}$

16. Oralidad $^{22}$

17. Economía ${ }^{23}$

18. No afectación del orden público ${ }^{24}$

19. Multidisciplinariedad en el abordaje de la cuestión ${ }^{25}$

20. Interdisciplina ${ }^{26}$

21. El trabajo en redes ${ }^{27}$

22. Asistencia letrada de las partes ${ }^{28}$

23. Consideración especial de los intereses de los menores, personas con discapacidad y personas mayores dependientes ${ }^{29}$

24. Conformidad expresa de las partes para que personas ajenas presencien el procedimiento ${ }^{30}$

Del relevamiento realizado se desprende el reconocimiento de diferentes intensidades en la recepción normativa. Un núcleo de principios, reconocidos por la mayoría de las legislaciones y otros que, interviniendo en el sistema se encuentran más alejados de su núcleo y que, en principio, deberíamos cuestionar si integran el conjunto de principios o comprenden otra tipología. Entonces, podemos abordar el análisis desde un mapa que nos permita identificar la conexión de los principios plasmados en las diferentes normativas provinciales, estableciendo un grado de receptividad, bajo un criterio cuantitativo conforme la cantidad de normas que referencian cada uno de los enunciados.

También vale aclarar que siguiendo un criterio rígido de clasificación, solo se consideraron "principios" a los efectos del mapa- aquellos que fueron enumerados en un artículo bajo su título, entendiendo como voluntad del legislador que los mismos no sean desconocidos como tales. Cabe destacar que el orden establecido a partir de un criterio cuantitativo, integrado por la cantidad de normas nacionales o provinciales que contienen cada uno

\footnotetext{
${ }^{21}$ Nación, Ley $N^{\circ} 25.689$, artículo 7, se incorpora en virtud que el artículo menciona "En la primera audiencia el mediador deberá informar a las partes sobre los principios que rigen el procedimiento de mediación prejudicial obligatoria”, aunque no sea la extensión precisa del concepto. Buenos Aires, Ley 13951, Régimen de Mediación, artículo 1; Ley 13.433, Provincia de Buenos Aires, Mediación en lo Penal, artículo 3; Córdoba, Ley 8858, artículo 4; Corrientes, Ley de Mediación 5487, artículo 4 y Procedimiento de Mediación Civil y Penal, Ley 5931, artículo 4; Misiones, Ley XII 19 (antes Ley 4517), artículo 5; Salta, Mediación Ley 7324, artículo 4; San Juan, Ley 7454, artículo 2.

${ }^{22}$ La Pampa, Ley de Mediación Integral 2699, artículo 3; Misiones, Ley XII 19 (antes Ley 4517), artículo 5; Río Negro, Ley de Mediación 3847 (hoy P 3847), artículo 3; Tierra del Fuego, Ley de Mediación 804, artículo 2.

${ }^{23}$ La Pampa, Ley de Mediación Integral 2699, artículo 3; Misiones, Ley XII 19 (antes Ley 4517), artículo 5; Neuquén, Programa de Mediación Penal (Ley 2302, artículo 64), artículo 6; Río Negro, Ley de Mediación 3847 (hoy P 3847), artículo 3; Tierra del Fuego, Ley de Mediación 804, artículo 2.

${ }^{24}$ Misiones, Ley XII 19 (antes Ley 4517), artículo 5.

${ }^{25}$ Misiones, Ley XII 19 (antes Ley 4517), artículo 5.

${ }^{26}$ Tierra del Fuego, Ley de Mediación 804, artículo 2.

${ }^{27}$ Tierra del Fuego, Ley de Mediación 804, artículo 2.

${ }^{28}$ Tucumán, Mediación Previa Ley 7844, artículo 7.

${ }^{29}$ Nación, Ley $\mathrm{N}^{\circ} 25.689$, artículo 7.
} 
de los enunciados, no implica un análisis sobre un posible grado de superioridad de uno sobre otros, ya que como especificáramos anteriormente- cada principio prevalecerá sobre otro, conforme participan de un sistema complejo dado en una cultura, tiempo y lugar por lo tanto se alimentan y retroalimentan de ella, y pueden ser compartidos por las individualidades de sus disciplinas, complementándose, existiendo "en y a pesar" de la norma misma.

Creemos que en este sentido nos parece interesante citar a Francisco Diez, quien en una reciente entrevista (Castellanos:2014) sobre el desarrollo de la mediación en Argentina, sostuvo que "la manera en que veo el desarrollo de la mediación en la Argentina, va por ese lado, el de ayudar a que se extienda la práctica, ayudar a que la práctica tenga una reflexión paralela y que ella aporte a un modelo de Mediación local; o más que local, nacional. Un modelo que pueda servir por un tiempo y que luego sea cambiado por otro, enriqueciéndose, adaptándose a las necesidades de la práctica, ya que estas ciencias son muy dinámicas. Lo maravilloso de la Mediación es que comulga en esta concepción con un montón de hechos que están pasando en la sociedad y que tienen que ver con cambios sociales fundamentales".

Con las aclaraciones realizadas, podemos exponer una cartografía de aquellos principios que fueron receptados normativamente.

${ }^{30}$ Nación, Ley N² 25.689, artículo 7. 


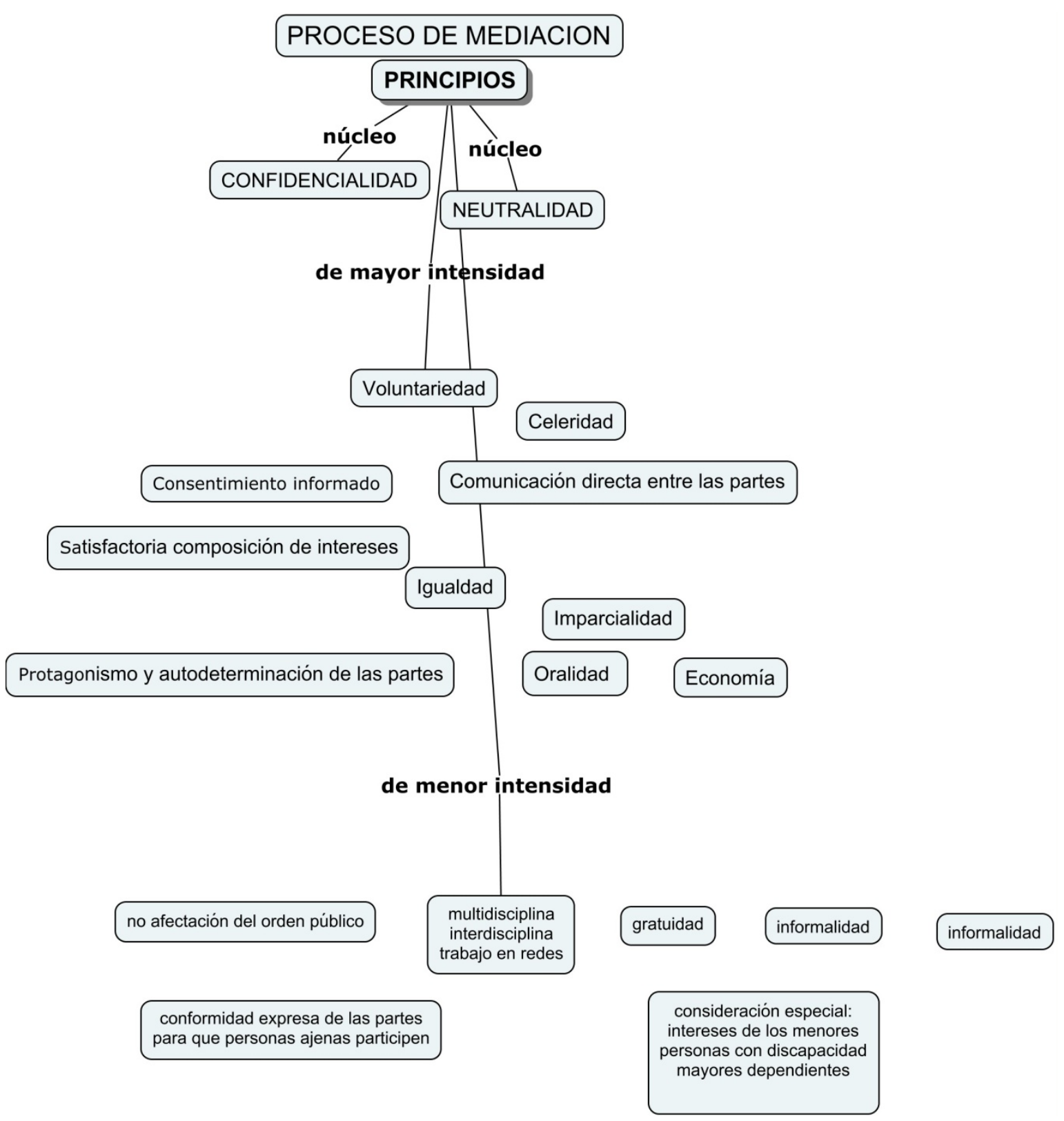

\section{SOBRE EL ALCANCE DE LOS PRINCIPIOS ENUNCIADOS}

\section{Núcleo}

Llamamos núcleo de los principios del proceso de Mediación a aquellos principios que fueron considerados en diecisiete (17) y doce (12) de las veintitrés (23) normativas analizadas, lo que revela la importancia que éstos tienen en la regulación sobre el proceso.

1. Confidencialidad

Entendemos que no existe duda que confidencialidad es entendida como un deber. Este deber tiene un alcance extensivo a las personas y a los contenidos (dichos y opiniones de los participantes) de los documentos que forman parte del proceso. 
Las personas que intervienen (mediadores, requirentes, requeridos, profesionales y otros) no podrán revelar fuera de la "mesa" lo sucedido en ella, tanto verbalmente cuanto en los documentos que se utilizan (actas, mera toma de notas, entre otras).

Este deber no es absoluto, cesa cuando entran a jugar otros principios: la voluntariedad de las partes, es decir un acuerdo expreso de éstas para exceptuarse de la misma y la no afectación del orden público, en cuanto del devenir del proceso surja la posible comisión de un delito.

Vemos como un principio evaluado como núcleo orientador de las acciones del proceso, puesto en juego con otros de diferente intensidad cuantitativa, pero relacionados con el sistema mayor limitan su alcance.

2. Neutralidad

Entendida como una actitud ordenada a los mediadores, en tanto representan una intermediación entre las partes que ponen a su "dirección" el proceso que transforme su conflicto.

El mediador es un tercero que dirige el proceso ajeno al conflicto, lo conduce y no toma decisiones resolutorias. Caram, Eilbaum y Risolía (2013:49) diferencian esta actitud del mediador como: *actitud de neutralidad interna $y$ *actitud de neutralidad externa. Respecto de la primera, sostienen que es "una auténtica e íntima convicción acerca de su posibilidad para interactuar con las personas en conflicto sin tomar partido por alguna de ellas, sin juzgar sobre su conducta o la conveniencia o no de los reclamos, alejando de su pensamiento la idea de quién tendrá la razón, y otorgando igual valor a los relatos de ambos. Respecto de la segunda, sostienen que el actuar del mediador "refleje imparcialidad".

Tan importante es éste principio que cuando el mediador se viera afectado en su neutralidad dentro del proceso, debe apartarse de la mediación. Suponemos que si el fin de la técnica es que las personas decidan sobre su conflicto, la pérdida de neutralidad de quien conduce el proceso distorsiona el resultado, ya que la posible resolución o no de la situación de conflicto estará teñida por cuestiones ajenas a las partes.

Es necesario aclarar que en el mapa realizado equiparamos lo entendido por imparcialidad al análisis expuesto sobre la neutralidad, ya que hay legislaciones que utilizan una u otra terminología.

\section{De mayor intensidad}

Llamamos "de mayor intensidad "de los principios del proceso de Mediación a aquellos principios que fueron considerados en cierta cantidad de normativas analizadas. Este análisis cuantitativo nos permite dar una tentativa escala de intensidad, calificándolas de "mayor" o "menor" intensidad en cuanto se encuentran más o menos cerca de los que fueron considerados núcleos. 


\section{Voluntariedad 131}

Con anterioridad referenciamos la contradicción que se vislumbra en cualquier análisis cuando se sostiene que la mediación es "voluntaria" y a poco de andar, la mayoría de las legislaciones establecen su obligatoriedad.

Ante esto cabe preguntarse ¿Cómo puede afirmarse la "voluntariedad” en un proceso "obligatorio”? Esta pregunta reafirma nuestra postura con relación a la existencia de principios que rigen los institutos a pesar de su regulación normativa. Esto es así, por cuanto podemos afirmar que la mediación es una técnica, cuyo espíritu pacificador va de la mano con el convencimiento de los participantes en proponer a la consideración de un otro, razones, reflexiones u otras ideas que permitan analizar el conflicto traído a la mesa. No existe coacción sino autocomposición.

Entonces ipor qué las normas dan carácter obligatorio a ciertos actos en el proceso? Creemos que la explicación puede ser sostenida en tres sentidos:

a. Lo obligatorio no es absoluto. Es decir, la obligatoriedad está impuesta dentro de la mal llamada Mediación judicial ${ }^{32}$ y orientada sólo al acceso al proceso, a la asistencia del requirente y requerido en el primer encuentro ${ }^{33}$ pero no a la obligación que éstos continúen (contra su voluntad) en el resto del proceso.

b. La obligatoriedad es relativa por cuanto, ante la falta de concurrencia del requirente o requerido, se da término a la mediación para continuar con el proceso judicial, imponiéndose una multa.

c. La imperiosa necesidad de imponer en la cultura jurídica actual la mediación, a fin de disminuir la cuantía de las causas que llegan a juicio, cuantía que atenta contra la verdadera eficacia del procedimiento tradicional.

En este último sentido, la obligatoriedad a la asistencia a una o más reuniones, podría justificarse en una política judicial en torno a "descongestionar" cuantitativamente el ingreso de causas al sistema tradicional como una forma que, lejos de atentar a su jurisdicción, contribuye a la eficacia y eficiencia de proceso judicial. No creemos que esta obligatoriedad relativa sea el modo de imponer la técnica, ya que atenta contra su espíritu.

\footnotetext{
${ }^{31}$ Receptado en $8 / 23$ normativas analizadas.

${ }^{32} \mathrm{La}$ Corte Suprema de Justicia de la Nación (CSJN) sostiene que en el caso de la jurisdicción nacional, el sistema de mediación es "conectado" con el Poder Judicial. Aclara que por mediación "conectada con los tribunales" se entiende el sistema en el que el Poder Judicial participa pero no administra. Esto lo hace otro organismo, en el caso de la Justicia Nacional, Civil y Comercial y Federal en lo Civil y Comercial dicha tarea la desarrolla el Ministerio de Justicia y derechos Humanos de la Nación, que es responsable de la capacitación de los mediadores, de las instituciones habilitadas para formarlos, etc. Sí, en cambio, el Poder Judicial responde en forma conjunta con el ente administrador en lo que respecta a la calidad del servicio, en tanto función de la administración de justicia. http://www.maparegional.gob.ar/accesoJusticia/public/verDetallePais.html?codigoPais=ar, búsqueda del 24 de septiembre de 2015 .

${ }^{33}$ Ver que leyes pueden indicar primer y segundo, la ley nacional establece el 1 y 2 ?
} 
Políticas activas de información y concientización a la sociedad son necesarias para dar paso a la voluntariedad plena.

\section{$\underline{\text { Celeridad }}^{34}$}

Este principio forma parte del carácter dinámico del proceso. La celeridadse encuentra entre las ventajas que se ponderan sobre la utilización de la mediación como alternativo al sistema judicial tradicional ${ }^{35}$, marcando la diferencia con procesos de heterocomposición de extensos plazos procesales.

Lo cierto es también que hay cierta diferencia entre la mal llamada "mediación judicial" y la "mediación extrajudicial". En las distintas regulaciones la "mediación judicial obligatoria” tiene plazos generales que cumplir, por ejemplo la ley 8858 de la Provincia de Córdoba, establece en su artículo 25: "El plazo para la mediación será de hasta sesenta (60) días hábiles a partir de la primera audiencia. El plazo podrá prorrogarse por acuerdo de las partes, de lo que deberá dejarse constancia por escrito, con comunicación al Centro Judicial de Mediación y al Tribunal actuante".

En cambio, en sede extrajudicial la mediación no tiene plazos perentorios, aunque la experiencia indica que es poco factible que los tiempos puedan medirse en años. Las mismas legislaciones le otorgan un sentido diferente a una u otra tipología, así la ley cordobesa 8858, cuando en el título III regula la "mediación en sede extrajudicial" extiende el alcance de las normas dirigidas a la "mediación en sede judicial" solo aquello que corresponda, creemos que entonces se libera esta imposición de tiempos máximos impuesta a la "mediación en sede judicial".

\section{$\underline{\text { Consentimiento informado }}{ }^{36}$}

Highton (2015) sostiene que "La doctrina del consentimiento informado lleva ínsita una polémica de carácter ético. La autonomía de cada persona para tomar decisiones se ve contrastada con el deber del profesional de usar su mejor juicio y habilidad para maximizar el servicio en general y de cada usuario en particular. Así, el tema queda resumido en quién tiene derecho a tomar la decisión final”. Destaca la autora que existe una actitud paternalista en la toma de decisiones por parte de los profesionales. Así, un abogado decide el decurso procesal de una situación de conflicto porque, supone y así fue formado, es un profesional apto para tomar una decisión técnica.

Reconocemos dos facetas de la cuestión sobre el consentimiento informado.

\footnotetext{
${ }^{34}$ Receptado en $8 / 23$ normativas analizadas.

${ }^{35}$ En este sentido ver HIGHTON, Elena I.; ALVAREZ, Gladys.Ob.Cit., CARAM, María Elena; EILBAUM, Diana Teresa y RISOLIA, Matilde. Ob. Cit., entre otros.

${ }^{36}$ Receptado en $7 / 23$ normativas analizadas.
} 
La primera es la relación cliente - profesional. En ésta el profesional tiene el deber ético de ponderar las distintas estrategias posibles ante el caso puesto a su consideración e informar al cliente lo que, a su entender, son las estrategias a plantear y sus eventuales consecuencias. Los profesionales hoy deberán echar mano a todas las estrategias posibles, entre las que sin dudas se incluyen los métodos autocompositivos (entre los que se encuentra la mediación) como los heterocompositivos (de prevalencia el judicial). Esta faceta excede el marco legal regulatorio de la mediación para adentrarse en cuestiones de ética profesional.

La segunda faceta es pensar el principio del consentimiento informado puesto en acción en una mesa de mediación. Según Highton (2015) la doctrina del consentimiento informado se desarrolló sobre la base de dos valores: a) el principio de la autonomía de la voluntad, y b) el principio de la maximización del bienestar; y en este sentido sostenemos que la cuestión se traslada del profesional que acompaña a una de las partes (requerido o requirente) al mediador. Esto es así, porque en la mediación no existe obligación alguna de asistir con un abogado patrocinante (por lo menos en sede extrajudicial), las personas pueden requerir la participación de un mediador y discutir frente a él sus posiciones.

¿Qué información debe tener el consentimiento en el procedimiento de mediación? Creemos que el mediador en la etapa de "discurso inicial" deberá explicar y garantizar que las partes comprendan cuestiones sobre: *tipo de proceso y su implicancia, *alcances de la potestad del mediador y su relación con las partes, * posibilidad de acuerdos previos de las partes, ${ }^{*}$ deber de confidencialidad de los participantes (puede o no ser por escrito), ${ }^{*}$ modos de llevar adelante el procedimiento y toda otra circunstancia que competa al ámbito de la mediación.

Los términos "explicar y garantizar" que utilizamos se explican en el marco de las cuestiones puestas en valor (el consentimiento en su máxima expresión) y en los tipos de mediaciones que existen, podemos ejemplificar con las mediaciones interculturales (donde suponen que intervienen personas de distintas culturas e idiomas), las escolares, entre otras.

Si pensamos en una técnica que promueve la autocomposición de una situación de conflicto, debemos asegurar la autonomía de la voluntad de sus participantes, autonomía de decisión que -sin dudas- en una de sus manos lleva la información como parte de su expresión.

\section{$\underline{\text { Comunicación directa de las partes }}{ }^{37}$}

La comunicación directa de las partes es un principio que se encuentra en igual posicionamiento en el mapa realizado. Esto podría dejarnos inferir que la comunicación juega un papel importante dentro de la mediación.

\footnotetext{
${ }^{37}$ Receptado en $7 / 23$ normativas analizadas.
} 
Creemos es el eje de la técnica, ya lo dicen las definiciones de Mediación enunciadas. Señalan Watzlawick, Beavin y Jackson (1985:17) que la comunicación es una condición sine qua non de la vida humana y el orden social ${ }^{38}$. También es obvio que desde el comienzo de su existencia, un ser humano participa en el complejo proceso de adquirir reglas de la comunicación, ignorando casi por completo en qué consiste ese conjunto de reglas, ese calculus de la comunicación humana. La "comunicación" de las partes es una de las problemáticas a analizar y comprender en la relación de conflicto traída a la mesa de mediación.

La comunicación "directa" entre las partes como principio, exige del mediador desplegar las diferentes estrategias ordenadas a la recomposición del dialogo cooperativo.

\section{$\underline{\text { Satisfactoria composición de intereses }}{ }^{39}$}

Creemos que es un principio utópico. ¿Como medir la satisfacción de intereses? Que mandato de principio se da cuando no existe la intervención de terceros como decisores? ¿Debemos suponer que las partes han satisfecho sus intereses si han llegado a un acuerdo?

Si se reconoce a la satisfactoria composición de intereses como un principio y, conforme la definición de principios que construimos anteriormente, como un "criterio axiológico ..." quedará para las partes orientado el compromiso de sus decisiones hacia la "satisfacción de intereses" y para el mediador la obligación de informarlo en el momento del proceso en que se perfecciona el principio de consentimiento informado.

\section{Igualdad ${ }^{40}$}

La igualdad entendida como "igualdad de trato, derechos, obligaciones" de las partes y para con ellas.

\section{$\underline{\text { Protagonismo y autodeterminación de las partes; oralidad y economía }}{ }^{41}$}

Agrupamos los tres principios enunciados a los efectos del análisis por compartir la cualidad de definir el procedimiento como tal. Es así, por cuanto en la mediación, la participación de las partes es esencial en el proceso, en cuanto están dirigidas a su autodeterminación. ¿Quién más que ellas mismas son las que mejor pueden decidir en la satisfacción de sus intereses? Parece que concebir el protagonismo y la autodeterminación como principios

\footnotetext{
${ }^{38}$ Estos autores participan de la teoría pragmática de la comunicación y desarrollan cinco axiomas exploratorios de la comunicación que compartimos en el análisis que sobre el tema se imparte en la cátedra de "Teorías del Conflicto y la Decisión. Métodos de Resolución Pacífica de Conflictos” de la Facultad de Derecho y Ciencias Sociales de la UNC: *imposibilidad de no comunicar; *niveles de contenido y relaciones en la comunicación; * puntuación en la secuencia de los hechos; *comunicación digital y analógica e *interacción simétrica y complementaria, que pueden profundizarse en la obra citada.

${ }^{39}$ Receptado en 6/23 normativas analizadas.

${ }^{40}$ Receptado en 6/23 normativas analizadas.
} 
supone la idea que la representación del sujeto será la excepción y no la regla. También, que ésta excepción estará marcada por las normativas legales que recogen el principio de autodeterminación por sobre la restricción de decisiones ${ }^{42}$.

Oralidad, en cuanto al modo del procedimiento, es la regla. Son pocos los instrumentos escritos que "deben" utilizarse en el proceso. Si consideramos la mediación dentro del proceso judicial, conforme la normativa que se trate, existen algunos instrumentos que deben ser por escrito, por caso -y en la generalidad- el acuerdo. Si discurrimos sobre la mediación fuera de sede judicial, serán normas de practicidad las que lleven a realizar documentos escritos (notificaciones, acuerdos), todos guardando el principio de confidencialidad.

Economía, concepto que gira en torno a los costos del proceso. Para comprender este principio se debe entrar en comparación con otros parámetros y así, presuponemos, que lo es en necesaria comparación con el procedimiento judicial. De hecho, es uno de los ítems que se ponen de resalto cuando se habla de las ventajas de la mediación, junto con otro ya analizado, la celeridad.

\section{De menor intensidad}

Llamamos "de menor intensidad" de los principios del proceso de Mediación a aquellos principios que fueron considerados en cierta cantidad de normativas analizadas. El análisis cuantitativo que nos permitió dar una tentativa escala de intensidad, al ser receptados por solo una normativa nos permitió calificarlas de "menor" intensidad, encontrándose -en el mapa- alejadas de los núcleos.

\section{No afectación del orden público ${ }^{43}$}

Este principio así tomado está enumerado por solo una de la normativa analizada, (Acordada 3964, anexo A, artículo primero), pero la mayoría de las restantes establecen como exclusión de competencia temática expuesta a Mediación, todas las cuestiones de orden público. Es decir, la afectación del orden público está tratada no como un principio sino como una controversia excluida del procedimiento de Mediación.

El término "orden público", señala Drnas de Clement (2015), en los países de tradición civilista se refiere a las reglas no escritas que hacen a la estructura jurídica básica indispensable en una sociedad dada para permitir la convivencia social ordenada, lo que incluye la protección de los derechos humanos fundamentales y siguiendo a

\footnotetext{
${ }^{41}$ Receptados en 4/23 normativas analizadas.

${ }^{42}$ En este sentido ver: ${ }^{*}$ la comprensión del nuevo Código Civil y Comercial (Argentina) sobre capacidad progresiva, ${ }^{*}$ l derecho del niño a ser escuchado, entre otros.

${ }^{43}$ Receptado en $1 / 23$ normativas analizadas.
} 
Roel de Lange ${ }^{44}$, señala el carácter multifacético del orden público.

La no afectación del orden público no podemos considerarla un "principio" en términos estrictos, concordamos entonces con la metodología generalizada en cuanto a su enunciación como controversia excluida al procedimiento, todo en virtud que la calificación de "orden público" implica un control externo a la decisión de las partes, con nortes normativos e imperativos que exceden la autocomposición de intereses.

\section{Gratuidad 45}

La gratuidad solo está establecida como principio del procedimiento en el caso de la ley 2451 de la Ciudad Autónoma de Buenos Aires (CABA), ley aplicable al régimen procesal penal juvenil, es decir a aquellas personas menores de dieciocho (18) años. Creemos que lo es en carácter excepcional, en virtud de las cuestiones puestas en juego y los principios que rigen el régimen penal juvenil.

\section{$\underline{\text { Informalidad }}{ }^{46}$}

La informalidad como principio está también enunciado en una sola de las normativas analizadas, precisamente como principio del procedimiento en el caso de la ley 2451 de la Ciudad Autónoma de Buenos Aires (CABA), ley aplicable al régimen procesal penal juvenil. Pero en orden de verdad, a pesar de estar solo enunciada en una normativa, la informalidad es un principio que rige en la técnica "a pesar" de no encontrarse enunciada legislativamente.

González de la Vega (1997:54) al reflexionar sobre el principio aplicado al proceso civil, sostuvo que el principio de formalismo y su contrapartida, el de flexibilidad o instrumentalidad de formas, postula que la actividad que se cumple en el proceso debe llevarse a cabo de acuerdo a ciertas condiciones de lugar, de tiempo y de modo. Reconoce también que en el moderno derecho procesal se postula una formulación intermedia denominada "adecuación de las formas", "de adaptabilidad" o "de elasticidad o flexibilidad". Termina afirmando que se propicia el establecimiento de condiciones mínimas que deben regir el cumplimiento de la actividad, y a la vez se permite la flexibilidad en otros supuestos.

Esta conclusión puede realizarse análogamente al reflexionar sobre el proceso de Mediación. Esta técnica tiene un acto de principio (apertura, discurso inicial) y un acto de final (finalización del proceso con o sin acuerdo), entre estos actos necesarios existen otros (audiencias conjuntas, privadas, continuaciones, etc) que se concretarán conforme el mediador (verdadero director del proceso) pulse en las conversaciones que se

\footnotetext{
${ }^{44}$ DE LANGE, Roel. "The European public order, constitucional principles and fundamental right", Erasmus L. Rev. 3 (20072008), en DRNAS DE CLEMENT, ZLATA. Ob. cit., pág. 11, www.acaderc.org.ar (búsqueda del 19 de octubre de 2015).

${ }^{45}$ Receptado en $1 / 23$ normativas analizadas.

${ }^{46}$ Receptado en $1 / 23$ normativas analizadas.
} 
mantengan en su mesa. Es decir, la informalidad planteada -sin dudas- no es absoluta, todo acto marca un principio y una conclusión, que rige en todo proceso de Mediación, sea en sede judicial como extrajudicial.

\section{Multidisciplinariedad en el abordaje de la cuestión, interdisciplina, trabajo en redes ${ }^{47}$}

La multidisciplina, interdisciplina y el trabajo en redes no parecen ser principios, en el sentido del concepto que construimos. En verdad son metodologías de abordaje de estudio de una ciencia ${ }^{48}$, metodologías generosas que comparten -en diferentes modos- conceptos, formas de abordajes del objeto de estudio o análisis, por lo que no comprendemos su incorporación dentro de un artículo titulado específicamente "principios" dentro de una norma.

Consideración especial de los intereses de los menores, personas con discapacidad y personas mayores dependientes ${ }^{49}$

Esta enunciación realizada tiene un alcance que excede su cristalización en una normativa de procedimiento. Esto es así, por cuanto la protección de los colectivos descriptos son norma de carácter constitucional, debido a las convenciones internacionales que integran el llamado "bloque constitucional" (artículo 75, inc. 22, CN... La Declaración Americana de los Derechos y Deberes del Hombre; la Declaración Universal de Derechos Humanos; la Convención Americana sobre Derechos Humanos; el Pacto Internacional de Derechos Económicos, Sociales y Culturales; el Pacto Internacional de Derechos Civiles y Políticos y su Protocolo Facultativo; la Convención sobre la Prevención y la Sanción del Delito de Genocidio; la Convención Internacional sobre la Eliminación de todas las Formas de Discriminación Racial; la Convención sobre la Eliminación de todas las Formas de Discriminación contra la Mujer; la Convención contra la Tortura y otros Tratos o Penas Crueles, Inhumanos o Degradantes; la Convención sobre los Derechos del Niño; en las condiciones de su vigencia, tienen jerarquía constitucional.. Convención sobre los Derechos de las Personas con Discapacidad aprobada por ley 26.378).

\footnotetext{
${ }^{47}$ Receptados en $1 / 23$ normativas - diferentes cada una- de las analizadas.

${ }^{48}$ Morin reflexiona sobre el trabajo transdisciplinario, este abordaje de estudio supera aún lo planteado en las distintas legislaciones, multidisciplina, interdisciplina y trabajo en redes. Así plantea: "toda realidad conocida (el átomo, la molécula, la célula, el organismo, la sociedad) puede ser concebida como sistema "es decir como asociación combinatoria de elementos diferentes", significa que para él la ciencia, los procesos culturales y la subjetividad humana están socialmente construidos, recursivamente interconectados, y constituyen un sistema abierto. Esto lleva a Morin a situarse en el nivel de lo transdisciplinario, que permita concebir al mismo tiempo, tanto la unidad como la diferenciación de las ciencias. Interesantes reflexiones que pueden ampliarse en http://www.edgarmorin.org/que-es-transdisciplinariedad.html, búsqueda del 19 de octubre de 2015.

${ }^{49}$ Receptado en $1 / 23$ normativas analizadas.
} 
$\underline{\text { Conformidad expresa de las partes para que personas ajenas presencien el procedimiento }} \underline{\underline{50}}$

A pesar de su enumeración expresa creemos que puede ser considerado como una expresión del principio de autocomposición que, a fin de no reiterar conceptos, desarrollaremos en el título a continuación.

\section{De otro principio de la mediación ("a pesar").}

Alejados de los textos legales argentinos y anteriores a estos, doctrina nacional e internacional exponían sobre los principios de la mediación. Fuera de los textos legales, la referencia es directa a la técnica en sí, aplicable judicial como extrajudicialmente.

Al momento de definir principios, nos enrolamos en la postura que estos existen "en y a pesar" de la norma, que participan de un sistema complejo dado en una cultura, tiempo y lugar por lo tanto se alimentan y retroalimentan de ella, y pueden ser compartidos por las individualidades de sus disciplinas, complementándose. En esa inteligencia es que enunciaremos aquellos principios que, sin ser enunciados en las leyes, complementan y direccionan su espíritu.

La Mediación ostenta como caracterización la posibilidad que las partes logren la autocomposición de su conflicto. Sin embargo, éste "carácter" tan diferenciador del proceso inquisitivo no es considerado un principio del método que estudiamos, sino una de sus características. Las leyes analizadas no enumeran en su discriminación dogmática la autocomposición como un principio.

Creemos que es hora de preguntarnos, encuadrados en el concepto de principios que enunciáramos, si la autocomposición puede abandonar la categoría de "característica" para considerarla como un principio que rige a la Mediación "a pesar" de la norma.

Folber y Taylor (1992:27) sostienen que la mediación es un proceso que hace hincapié en la propia responsabilidad de los participantes de tomar decisiones que influyen en sus vidas. Por lo tanto, constituye un proceso que confiere autoridad sobre sí misma a cada una de las partes. Esta afirmación, no ajena a la doctrina que sustenta este trabajo, subraya la importancia del rol de las partes en el proceso de Mediación, ellas son las que "toman las riendas" de su conflicto, las que se comprometen y no delegan en manos de un tercero la resolución del mismo. La autocomposición en estos términos, no es una simple característica del proceso, es un verdadero principio que guía las acciones de las partes, de los mediadores y, también, de la ley misma. No puede concebirse una ley que en sus enunciados no tenga como "meta-punto de vista", la autocomposicióny no puede concebirse al método aplicado sin que éste importante principio ilumine las acciones y estrategias planteadas para el desarrollo del proceso.

\footnotetext{
${ }^{50}$ Receptado en $1 / 23$ normativas analizadas.
} 
Visto así, la autocomposición será un principio que rige "a pesar" que las normas no lo enuncien como tal, ya que es un criterio axiológico que se transforma -a nuestro entender- en un "meta-punto de vista" que observa el procedimiento, sus estrategias y acciones.

\section{$\underline{\text { Redefinimos la cartografía, "en y a pesar" de la norma }}$}

Es el momento de proponer redefinir la cartografía de principios del punto 4.1. que solo consideraba aquellos principios enumerados como tales en las normas analizadas, para agregar el de autocomposición.

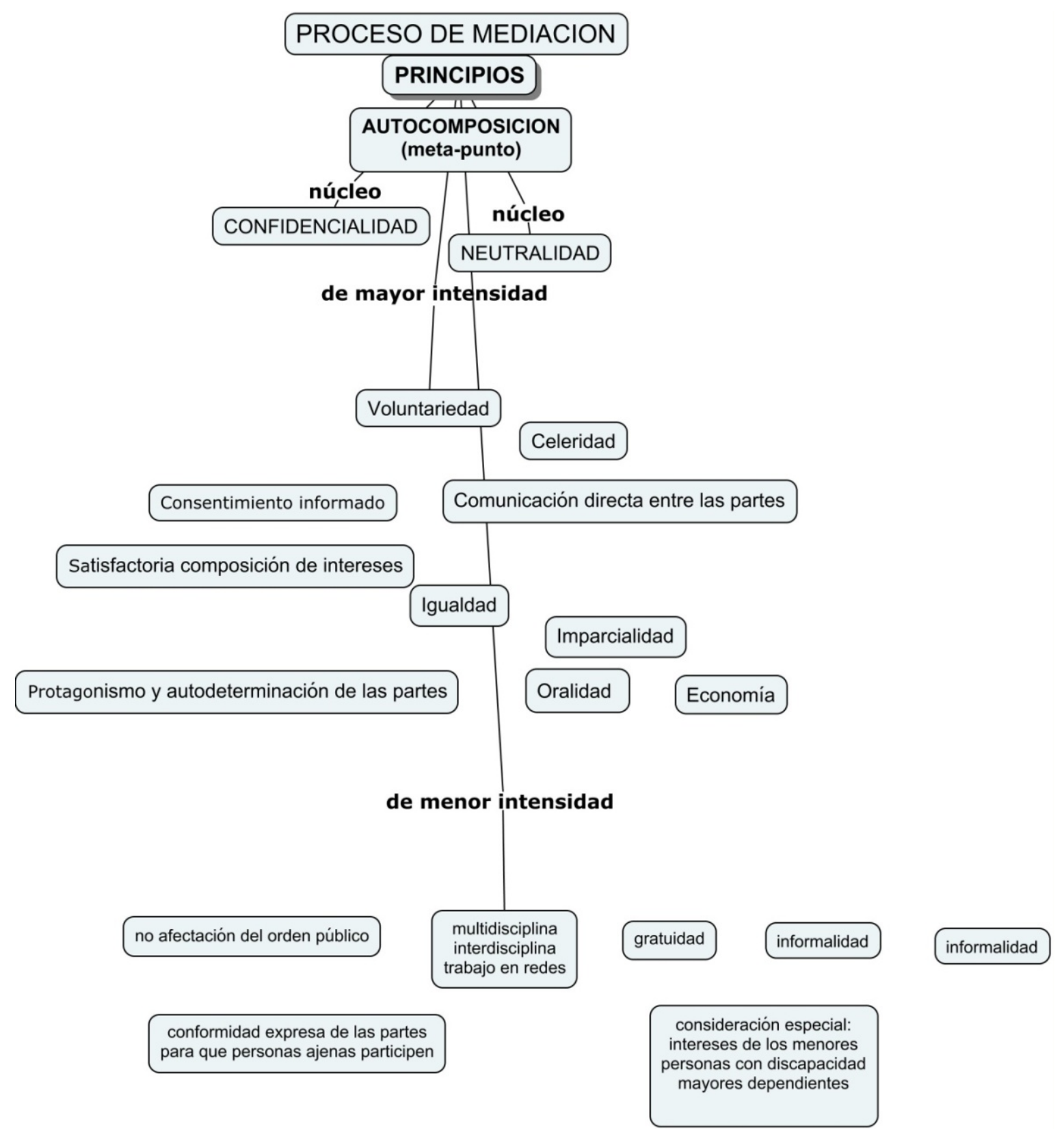




\section{CONCLUSIONES}

La Mediación es una técnica que en su aplicación conlleva un proceso con principios que pueden o no estar enunciados en las leyes que la rigen. Sin dudas, ésta técnica integra el sistema de resolución de conflictos que la cultura de éste momento integra como tal, cuando prevalece la cultura de la paz.

Del análisis comparativo surge con claridad que existe una categoría de principios que sostienen con mayor intensidad la concepción de la técnica en sí, es decir, aquella que conjuga recursos que se ordenan en un proceso que, en su origen y alejado del procedimiento judicial, pretende acompañar en sintonía y con cierta organización, cuya flexibilidad acompañe el delicado devenir de la relación de conflicto confiada a su tratamiento. Estos principios, de tal intensidad que los clasificábamos como núcleos, son el de confidencialidad y neutralidad sumándose, como un "meta-punto de vista", el de autocomposición.

Así vemos que sus principios se encuentran enunciados en leyes, pero la existencia de éstos no se agota en su enumeración en las mismas sino que se orientan profundamente hacia la autocomposición de la situación de conflicto que esgrimen las partes en el transcurso del desarrollo de la Mediación, principio que hace del mediador un tercero que no decide y que empodera a las partes para que construyan una solución cooperativa que permita transformar su relación.

Autocomposición, confidencialidad y neutralidad, son el basamento de la Mediación, son "faros" que guían su devenir y cuyo cumplimiento hace a la esencia misma de la resolución de conflictos en forma pacífica.

Como meta-punto de vista, podemos afirmar encuadrados en el concepto de principios que enunciáramos, que la autocomposición abandona la categoría de "característica" para pasar a ser un principio que rige a la Mediación "a pesar" de la norma.

Los principios existen "en" las leyes o "a pesar" de no estar enumerados como tales en ellas. Así, no todas las legislaciones comparten exactamente la misma enumeración, pero esto no hace que la conclusión sea que no existen, que no iluminan el proceso de la técnica en esa jurisdicción, muy por el contrario, creemos que todos participan del proceso en todas las jurisdicciones porque son la esencia de la técnica misma y, de entre ellos, el que -como criterio axiológico- los guía es el de la autocomposición. 


\title{
A LOOK OVER PRINCIPLES IN THE MEDIATION PROCEDURE
}

\author{
Summary \\ Mediation is presented as a technique applied to pacific resolution of conflicts alternative to the judicial \\ argentinean system. This essay portraits the specific principles of Mediation, comparing them to the enunciation \\ of national and local legislative principles, the determination of them in the doctrine, finalizing with a critic \\ evaluation about determination and hierarchy of the Mediation principles, from a complex view. As a study that's \\ forms part of an investigation program about conflict resolution in families, the analysis is a contribution that \\ complements the ones applied to family conflicts process of resolution.
}

Keywords: Mediation - Principles - Pacific Resolution of Conflicts- Processes of resolution of conflicts in Argentina.

\section{BIBLIOGRAFÍA}

CAIVANO, Roque J. Abogacía moderna vs. Abogacía tradicional. Los sistemas alternativos de solución de disputas como forma de ser más eficientes, La Ley 1994-E, Buenos Aires, p. 885.

CAPON FILAS, Rodolfo. Sobre los principios del derecho del trabajo y su importancia en la actualidad, DT 2010 (febrero), pág. 279.

CARAM, María Elena; EILBAUM, Diana Teresa y RISOLIA, Matilde. Mediación. Diseño de una práctica, 4ta Edición actualizada y ampliada, Editorial Astrea, CABA, 2013.

CASTELLANO, Juan José. “Reflexiones desde la práctica, entrevista con Francisco Diez”, La Fuente-Revista de Psicología y Ciencias Humanas, Año XIV, n49, pág. 13.

DRNAS DE CLEMENT, Zlata. Los principios generales del DIP como base del orden público internacional, www.acaderc.org.ar (búsqueda del 19 de octubre de 2015).

FERREYRA DE DE LA RUA, Angelina; GONZÁLEZ DE LA VEGA DE OPL, Cristina. Medios de Prueba, Advocatus, Córdoba, 1994.

FOLBER, Jay P.; TAYLOR, Alison. Mediación. Resolución de Conflictos sin litigio, Limusa, México, 1992.

GARCIA CALVO, Manuel. Interpretación y argumentación jurídica: Trabajos del Seminario de Metodología Jurídica (volumen), Prensas Universitarias Zaragoza, España, 1995.

GARCIA CIMA DE ESTEVE, Elena. Derecho por principios en los Estados constitucionales contemporâneos, inédito, 2015.

Un diseño de mediación- Modelo del Colegio de Escribanos de Córdoba, Argentina; Alveroni Ediciones, Córdoba, 2001.

GONZALEZ DE LA VEGA, Cristina. "Principios que gobiernan el proceso", Derecho Procesal Civil, Teoría del Proceso (Jorge ZINNY- Director), Ed. Atenea, Córdoba, 1997. 
HIGHTON DE NOLASCO, Elena. Consentimiento Informado en RAD, http://www.fundacionlibra.org.ar/revista/articulo3-4.htm, búsqueda del 28 de septiembre de 2015.

HIGHTON, Elena I.- ALVAREZ, Gladys. Mediación para resolver conflictos, AD-HOC S.R.L. (tercera reimpresión), Buenos Aires, 2008.

MORIN, Edgar. Introducción al pensamiento complejo, Editorial Gedisa S.A., España, 1990.

WATZLAWICK, Paul; BEAVIN BAVELAS, Janet y JACKSON, Don. Teoría de la Comunicación Humana, Ed. Herder, Barcelona, 1985.

Trabalho enviado em 03 de março de 2016.

Aceito em 16 de junho de 2016. 